\title{
A CONCILIAÇÃO NO BRASIL E A SUA IMPORTÂNCIA COMO TRATAMENTO ADEQUADO DE CONFLITOS
}

\author{
CONCILIATION IN BRAZIL AND ITS IMPORTANCE AS ADEQUATE TREATMENT OF \\ CONFLICTS
}

\begin{abstract}
Adriana Pereira Campos
Doutora em História pela Universidade Federal do Rio de Janeiro. Professora permanente dos Programas de Pós-Graduação stricto sensu em Direito e em História da Universidade Federal do Espírito Santo. Pesquisadora Produtividade (2) do CNPq e Coordenadora do Projeto Opinio Doctorum financiado pela Fundação de Pesquisa e Inovação do Estado do

Espírito Sanato - FAPES. E-mail: acampos.vix@gmail.com
\end{abstract}

João Vitor Sias Franco

Bacharel em Direito pela Universidade Federal do Espírito Santo, pós-graduado em Direito Tributário pela Fundação Getúlio Vargas e mestrando no Programa de PósGraduação stricto sensu em Direito da Universidade Federal do Espírito Santo. E-mail: joaovitorsias.adv@gmail.com

Recebido em: 09/08/2017

Aprovado em: 13/11/2017

Doi: $10.5585 /$ rdb.v18i7.763

RESUMO: Neste artigo, busca-se discutir a criação do instituto da Conciliação no Brasil, bem como as transformações advindas dele, de modo a compreender seu papel como meio de realização da justiça. Como se observará, a cultura jurídica de mais longa duração no país foi a de tornar a conciliação um instrumento de concretização da garantia constitucional de duração razoável do processo, voltada à conservação da ordem pública, de modo a dirimir conflitos e contendas antes que se transformassem em demandas judiciais. No Império, a conciliação, prevista constitucionalmente, separava-se absolutamente do processo, mas consistia em procedimento necessário para início de qualquer ação. Na República, porém, a conciliação se transformou, de ato jurídico condicional, em mera técnica processual. Desde a Constituição de 1988, a conciliação voltou à condição de determinação constitucional, tendo sido restituída também às antigas autoridades leigas conhecidas como juízes de paz. Tendo presente tais fatores, este artigo apresenta como a conciliação deixa de ser apenas um ato jurídico condicional no início do processo para se transformar em técnica processual, recebendo grande destaque no Novo Código de Processo Civil do país instituído em 1988.

Palavras-chave: Conciliação. História da conciliação no Brasil. Duração razoável do processo. Justiça.

ABSTRACT: In this paper, we discuss the creation of the Institute of Conciliation in Brazil, as well as the transformations induced by it and its role as an instrument of delivering justice. As will be seen, the country's longest-standing legal culture has consisted in making conciliation an instrument for implementing the constitutional guarantee of a reasonable time duration of the process, aimed at the maintenance of public order, so as to resolve disputes before they become 
lawsuits. During the Empire, the conciliation, a constitutionally established step, legally preceded the judicial process, its being a necessary procedure to commence any legal action. When the country became a Republic, however, conciliation was transformed from a conditional legal act into a mere procedural technique. Since the 1988 Constitution, though, conciliation has returned to the condition of a constitutional determination, which also reinstated the former lay authorities known as judges of peace. Keeping these factors in sight, the present paper shows how conciliation ceased to be just a conditional legal act to start a process to become a prominent procedural technique assured by the New Code of Civil Procedure which came into force in 1988.

Key-words: Conciliation. History of Brazilian conciliation. Reasonable duration of the proceedings.

SUMÁRIO: Introdução. 1. A conciliação como dever de honestidade. 2. A conciliação como ato judicial, mas não processual. 3. Formalismo processual e declínio da conciliação. 4. Conciliação como tratamento processual adequado. Conclusão. Referências Bibliográficas.

\section{INTRODUÇÃO}

Em razão da constatada insuficiência do Poder Judiciário em solucionar a enorme quantidade de litígios da sociedade novos meios de solução de conflitos ganharam destaque nos debates jurídicos. A principal crítica que aponta essa insuficiência dirige-se à morosidade na tramitação dos processos, a qual coloca em risco as garantias constitucionais de acesso à Justiça e de duração razoável do processo (CAYRES, 2012. p. 15). No entanto, a admoestação não se coloca apenas nesse plano. De modo mais abrangente, discute-se a conveniência de abordagens colaborativas no campo do judiciário. Juliana Demarchi (2007, p. 40) considera a autocomposição o meio mais apropriado para obtenção de resultados satisfatórios para todos os envolvidos, pois se trata de métodos com alcance diferente daquele obtido por meio das técnicas adversariais em que tudo o que uma parte ganha é retirado de outra.

Para Bárbara Chagas (2017, p. 101) os métodos colaborativos não devem ser designados como "meios alternativos" já que remeteriam ao sistema adjudicatório como via principal de resolução de conflito. Já a expressão "extrajudiciais" desconsideraria a possibilidade de a composição ocorrer também no Judiciário. Assim, Chagas (2017) considerou mais oportuna a locução apresentada pela Resolução n. 125/2010 do Conselho Nacional de Justiça (CNJ) de "tratamento adequado dos conflitos de interesse", in verbis, "Art. $1^{\circ}$ Fica instituída a Política Judiciária Nacional de tratamento dos conflitos de interesses, tendente a assegurar a todos o direito à solução dos conflitos por meios adequados à sua natureza e peculiaridade" (Grifa-se).

O novo Código de Processo Civil de 2015 reconheceu a necessidade de conferir tratamento adequado a cada tipo de litígio (DIDIER JR, 2015, p. 166). Não há, portanto, métodos principais ou alternativos, mas sim compatíveis ou não ao conflito levado aos tribunais. $\mathrm{O}$ comando do artigo 334 expressa essa compreensão:

Art. 334. Se a petição inicial preencher os requisitos essenciais e não for o caso de improcedência liminar do pedido, o juiz designará audiência de conciliação ou de mediação com antecedência mínima de 30 (trinta) dias, devendo ser citado o réu com pelo menos 20 (vinte) dias de antecedência.

No presente artigo, analisamos como a conciliação se tornou peça relevante para o desenvolvimento do sistema jurídico ao longo da história do ordenamento jurídico pátrio. Não incluímos neste artigo a mediação, pois entendemos, como leciona Alessandra Marques (2016), que se trata de instituto diverso da conciliação, embora ambos constituam formas de resolução 
consensual de conflitos. Na mediação, a terceira pessoa atua como "facilitadora da reconstrução da relação entre as partes por meio do restabelecimento do diálogo entre elas", já na conciliação, o terceiro pode adotar posição mais ativa, porém neutra, convertendo-a num processo consensual breve (MARQUES, 2016, p. 203).

Aborda-se o instituto do ponto de vista da cultura jurídica, de modo a levantar as diferentes compreensões de processo, justiça e direito que guiaram a estruturação da conciliação como tratamento de conflitos e harmonização social. O instituto da conciliação pode ser entendido como o método pelo qual as partes confiam a uma terceira pessoa, que guarda relação de imparcialidade, a função de aproximá-las, orientá-las e incentivá-las na composição dos seus interesses conflitantes, inclusive indicando proposições de acordo, para convencionarem uma solução aceitável para ambas, sem que tenham mais de contender quanto a esses interesses (MAGANO, 1985, p. 43 e MORAIS, 1999, p. 135). A conciliação consiste na resolução de conflitos das partes sem a necessidade da intervenção do poder jurisdicional, exercendo, assim, o papel de um equivalente jurisdicional.

Equivalentes jurisdicionais são as formas não-jurisdicionais de solução de conflitos. São chamados de equivalentes exatamente porque, não sendo jurisdição, funcionam como técnica de tutela dos direitos, resolvendo conflitos ou certificando situações jurídicas. [...] Os principais exemplos são a autotutela, a autocomposição e o julgamento de conflito por tribunais administrativos (solução estatal não jurisdicional de conflitos). (DIDIER JR. 2015, p. 164)

Além da possibilidade de se promover uma conciliação extrajudicial (externa ao processo), o ordenamento jurídico contém instrumentos para promover a conciliação endoprocessual, para que possam as partes chegar à melhor solução para o seu litígio, sem a necessidade de um terceiro (juiz) decidir por elas. Com essa finalidade, a Constituição Federal de 1988 previu a figura dos juízes leigos e a Lei n. 9.099/95 disciplinou a atuação desses perante os Juizados Especiais, com o objetivo de alcançar índices maiores de conciliação, bem como para auxiliar os magistrados na função jurisdicional. Nesse mesmo sentido, o Novo Código de Processo Civil trouxe inovações com o objetivo de estimular a conciliação das partes, colocando à disposição dessas o aparato estatal para incentivar a autocomposição.

\section{A CONCILIAÇÃO COMO DEVER DE HONESTIDADE}

A autocomposição das partes no Brasil também pertence a uma longa tradição do Império português. A instituição da conciliação surgiu como solução de concórdia das demandas durante o reinado de D. João II (1455-1495), que recebeu das Cortes a seguinte sugestão:

Outro si Senhor muitas demandas se não começariam e começadas cessariam e discórdias se acabariam se houvesse alguns homens de bem medianeiros que se entremetessem em meio à pacificar e meter concórdia e paz entre os desacordados e aquele que se mal querem [...] seja vossa mercê de mandardes às cidades e vilas de vossos Reinos que elejam dentre si dois bons homens ou mais se necessário for segundo os lugares forem que tanto que souberem alguns que se mal querem e andam desauridos ou para entrarem em demanda sobree algumas dívidas e heranças ou para julgarem as punhadas e irem a mal se metam a concordar e se trabalhem quanto puderem para meter entre eles paz e por si aqui se escusarem muitas demandas em vossos Reinos e morte e arruídos se evitarem (apud RIBEIRO, 1855, p. 179-180). 
Naquela época, o rei não pareceu entusiasmado com a providência proposta e respondeu apenas que não criaria semelhantes ofícios.

No século XVI, quando ainda desembarcavam os primeiros navios na América, as Ordenações Manuelinas consagraram a instituição em seu livro $3^{\circ}$, título XV, item I, como se observa no excerto abaixo:

E no começo das demandas dirá o Juiz a ambas as partes, que antes que façam despesas, e se entre ele os ódios e dissensões, se devem de concordar, e não curar de gastar suas fazendas por seguirem suas vontades, porque o vencimento da causa sempre é muito duvidoso: e isto, que dizemos de induzirem as partes à concórdia, não é de necessidade, mas somente de honestidade nos casos em que o bem poderem fazer; porém isto não terá lugar nos feitos crimes, quando os casos forem tais, que segundo as Ordenações a Justiça haja lugar (Transcreveuse do português Seiscentista).

As Ordenações Manuelinas foram editadas depois da compilação das fontes de direito em Portugal, providenciada pelo rei D. Afonso V (1432-1481), na forma de um código, cujo esforço datava ainda do reinado de D. João I (1357-1433) (SILVA, 1991). Dessa longa tradição, Portugal consolidara, no século $\mathrm{XV}$, o princípio da lei como expressão da vontade do príncipe. $\mathrm{O}$ imperador português, entretanto, não se comportava, consoante Nuno Silva (1991, p. 202), como "o rei bárbaro que costuma legislar só após ouvir o conselho de magnates, leigos e eclesiástico". A intensa atividade legislativa dos reis marcou, assim, aquela época em Portugal, uma vez que os monarcas passaram a legislar com abundância.

As Ordenações Manuelinas foram as primeiras a serem impressas em tipografia, apesar de certa dificuldade em vista do alto custo. Não obstante a distribuição de alguns milhares de exemplares, as ordenações conviviam com inúmeros diplomas avulsos que revogavam, alteravam ou esclareciam muitos de seus preceitos. Outras vezes, tais resoluções inovavam por meio de interpretações interpostas por assentos da Casa da Suplicação ou pelo próprio monarca (COSTA, 2011, p. 317-318).

Assim ocorreu com a reconciliação das partes disciplinada pelas ordenações. D. Manuel ordenou, pela edição também de uma resolução, que uma pessoa em cada vila ou lugar se responsabilizasse por tentar concertar as partes litigantes, sem o que não teria início qualquer demanda judicial. Curiosamente, a antiga proposta das Cortes em 1481 tornou-se realidade no século seguinte. Eis a resolução:

[...] E querendo dar ordem que as partes possam, quando quiserem sem temor dos ditos inconvenientes, fazer concerto, e que possam confessar tudo o que quiserem, sem receio das ditas confissões vir nenhum prejuízo quando se não acabarem de concertar, e bem assim como sempre haja em cada lugar uma pessoa virtuosa e de boa consciência e bem entendida que continuadamente esteja prestes para entender nos tais concertos por nos parecer que é grande serviço de Deus o bem assim de nossos súditos. Ordenamos e mandamos que em cada cidade vila ou lugar haja uma pessoa que para isso seja ordenada boa e virtuosa ou bem entendida a qual terá encargo como for requerido por algum litigante, em causa cível ou crime, em que a justiça não haja lugar ou posto que não seja requerido, como ele souber que algumas partes andam em demanda e discórdia ele fazer quanto puder e trabalhar por as concertar, mandando chamar cada uma das partes por si e ajuntando-as ambas quando convir, ou indo a casa de cada uma das ditas partes sendo de tal qualidade para ela. Ordenação e Regimento dos Concertadores de demandas dado por El-Rey D. Manoel em 25 de Janeiro de 1519 (apud RIBEIRO, 1855, p. 181). 
Quando assumiu o trono português, por direito de herança, D. Felipe II, rei também de Espanha, concentrou grande parte de suas atividades de governante à promulgação de leis. Aos portugueses garantiu, porém, a manutenção da tradição das leis pátrias. Sem abrir mão da modernização legislativa que promovera em Espanha, Felipe consagrou as novidades reformando as antigas ordenações manuelinas, mas em relação à conciliação conservou quase a mesma redação da norma anterior, como se pode conferir:

E no começo da demanda dirá o Juiz a ambas as partes, que antes que façam despesas, e se sigam entre eles os ódios e dissensões, se devem concordar, e não gastar suas fazendas por seguirem suas vontades, porque o vencimento da causa sempre é duvidoso. E isto, que dissemos de reduzirem as partes à concórdia, não é de necessidade, mas somente de honestidade nos casos, em que o bem poderem fazer. Porém, isto não haverá lugar nos feitos crimes, quando os casos forem tais, que segundo as Ordenações a Justiça haja lugar (Ord. Liv. 3, Tit. 20, 1 - Transcreveu-se do português Setecentista).

Pode-se questionar a efetividade dos mandamentos das ordenações, mesmo sob reinados poderosos como o de Felipe II. No entanto, deve-se ter em conta que, especialmente em Espanha e Portugal, houve fortalecimento e consolidação das leis fundamentais como estatuto do estado monárquico. $\mathrm{O}$ desenvolvimento teórico do conceito de lei fundamental integrou o pensamento jurídico lusitano como um dos pilares da sociedade política. Inclusive, a evolução constitucional portuguesa e, por consequência, brasileira beneficiou-se do aprofundamento do conceito de lei fundamental no Reino (HOMEM, 2003, p. 93 e 97).

De todo modo, até fins do século XVIII, a conciliação constante na legislação portuguesa, como ensina Ribas (1879, p. 149), constituía-se em "dever de honestidade" e não necessidade ou obrigação rigorosa para todos os casos. Embora constasse no livro III das Ordenações Manuelinas, os juízes concertadores podiam tentar ou não a conciliação como fase anterior ao processo, sem condicionar a demanda ao cumprimento desta como preliminar.

\section{A CONCILIAÇÃO COMO ATO JUDICIAL, MAS NÃO PROCESSUAL}

Na Constituição brasileira de 1824, o instituto da conciliação recebeu papel de destaque como procedimento prévio e obrigatório para se ajuizar demanda judicial. Pode-se, de certo modo, afirmar que a tradição lusitana da concertação se manteve em solo brasileiro mesmo depois do rompimento político. Inovou-se, contudo, a autoridade responsável por realizar o procedimento de conciliação e seu caráter de condição essencial para a lide:

Art. 161. Sem se fazer constar, que se tem intentado o meio da reconciliação, não se começará Processo algum.

Art. 162. Para este fim haverá juízes de Paz, os quais serão eletivos pelo mesmo tempo, e maneira, por que se elegem os Vereadores das Câmaras. Suas atribuições, e Distritos serão regulados por Lei. (Grifa-se, BRASIL, 1824)

A conciliação tornou-se, assim, preceito constitucional e não processual. Parece que houve grande influência francesa e espanhola na constitucionalização da prática de concertação dos conflitos. Na Constituição francesa de 1791, no capítulo sobre a organização do poder judiciário, definiu-se, no artigo 6, que "Os tribunais ordinários não podiam receber nenhuma ação civil, sem que lhes fosse justificado que as partes tivessem comparecido ou que o recorrente tenha citado a sua parte oposta contra mediadores para chegar a uma conciliação" (FRANÇA, 1791). A Constituição espanhola de 1812 também possuía dispositivo semelhante: "Sem fazer constar que se tentou um meio de conciliação, não se estabelecerá nenhum pleito" (ESPANHA, 
1812, art. 284). Observa-se, portanto, que a cultura constitucional do período transformava a conciliação num princípio organizador da justiça.

Curiosamente, a Constituição lusa previa a conciliação apenas nas causas que competiam aos juízes eletivos (PORTUGAL, 1822, art. 181). Já o Brasil, antecipou-se, em relação aos lusitanos, na criação dos juízes de paz com a função conciliadora, que somente sobrevieram em Portugal no ano de 1832 (CARVALHO, 1999). Tal como posto pela tradição de concertadores, a função do juiz de paz cabia a cidadãos eleitores, sem necessidade de formação jurídica ou conhecimento das leis, eleitos diretamente pela assembleia primária (CAMPOS, 2011).

Para José Murilo de Carvalho (1996, p. 341), o caráter eletivo do juiz de paz deve ser observado como elementar na construção da cidadania, pois significava a participação direta do cidadão no poder judiciário, independente de vínculo profissional (CARVALHO, 1996, p. 4). Nesse mesmo sentido, Adriana Campos e Ivan Velasco (2011) apontaram que as eleições diretas para o cargo de juiz de paz favoreceram a interiorização da política em lugares mais remotos do país e a formação da comunidade política. Slemian (2009, p. 186) considerou ainda que o instituto favoreceu a efetivação do poder judiciário "[...] por meio do reforço da descentralização do sistema, mediante à eleição de representantes locais."

Entre 1827 e 1841, o papel dos juízes de paz ganhou enorme alcance, pois também a ordem pública passou a ser responsabilidade dessas autoridades. Além da conciliação, os magistrados eletivos acumulavam funções policiais, judiciais (em casos menores), administrativas (como a divisão dos quarteirões e a nomeação de inspetores) e eleitorais (como a qualificação de votantes e eleitores da paróquia e o deferimento de justificativas de ausências) (MOTTA, 2013, p. 64-65). Em 1841, porém, a reforma do código processual criminal esvaziou as atribuições dos juízes de paz, principalmente aquelas ligadas à disciplina social, repassando-as aos delegados de polícia e juízes de Direito (FLORY, 1986, p. 266-277).

Segundo Thomas Flory (1986, p. 209), na primeira das reformas jurídicas liberais do Império, o juizado de paz foi sempre mais vulnerável à crítica conservadora, pois os juízes frequentemente abusavam de seu poder, faziam inimigos ou se convertiam em figuras chave nas disputas locais. Talvez se possa somar a essa explicação o fato de, no contexto da Regência, novas clivagens políticas como caramurus e exaltados terem assumido postos de juízes de paz. Esses agrupamentos de oposição aos moderados logravam, muitas vezes, êxito nas eleições para o cargo. Assim, parte dos juízes de paz eleitos divergia do conceito de ordem imposto pelo governo regencial. Os moderados perceberam, ademais, que os chefes de polícia e juízes de direito possuíam enormes limitações diante de autoridades locais com autonomia garantida em diversos corpos legislativos, como o Regimento dos Juízes de Paz, de 1828, e o Código de Processo, de 1832.

O então presidente da Província do Grão-Pará, Soares d'Andréa vinculava os juízes de paz aos cabanos, de modo que, em suas correspondências com a Corte, denunciava a "brandura" daqueles magistrados com as queixas e denúncias de sedição (MOURA, 2017). Em Porto Alegre, Rio Grande do Sul, certo magistrado eletivo, Manoel Vaz Pinto, foi processado e denunciado por conluio com os rebeldes, apesar dos avisos e ordens enviados pelo promotor da província (CODA, 2012, p. 94 e 99).

Apesar da perda, em 1841, de parte de suas atribuições adquiridas na década de 1830 pelos juízes de paz, a conciliação, sem a qual os processos não podiam iniciar, seguiu sob sua autoridade. Manteve-se ainda a alçada desse juízo sobre causas que excedessem a cem mil réis, salvas as fiscais e de raiz (d'OLIVEIRA, 1879). Acertadamente, Ribas (1879, p. 150) interpretou a conciliação como instituição de ordem pública, pois se destinava a evitar os litígios e manter a harmonia entre os cidadãos. Sem sua observância, não podia ser suprida e nem renunciada e a inobservância importava em nulidade absoluta. 
José Mendonça (1889) considerava a conciliação, conquanto fosse ato judicial, como procedimento destinado a evitar demandas. Na opinião do doutrinador, a conciliação precedia as ações cíveis e comerciais e não se confundia com essas últimas. Corrobora esse fato da conciliação como ato judicial, mas não processual, a Consolidação das Leis do processo civil, desenvolvida por Antônio Joaquim Ribas e seu filho Julio Adolpho Ribas, em seu artigo 185 a 200 (parte primeira), que previa a conciliação como procedimento prévio e necessário ao processo judicial, a ser desenvolvida perante os Juízes de Paz. Releva a opinião dos Ribas, pois se utilizava a aludida consolidação como referência de Código de Processo Civil, a partir da Resolução Imperial de 28 de dezembro de 1876, que lhe atribuiu força de lei.

\section{FORMALISMO PROCESSUAL E DECLÍNIO DA CONCILIAÇÃO}

Pelo que se viu dos textos de Ribas (1879) e Mendonça (1889), doutrinariamente o processo, no século XIX, se restringia apenas ao contencioso. Já a conciliação consistia num ato judicial constitucionalmente previsto para promover a ordem pública, via mediação dos conflitos. Para Jacques Poumarède (2014, p. 2), a prática de confiar a resolução de disputas e contendas a conciliadores não era nova na França e, como se viu neste artigo, nem o era em Portugal. É verdade, porém, que a constitucionalização do instituto tornou a filosofia conciliadora acessível a todos os cidadãos, prevenindo os incômodos e prejuízos de um longo processo.

Poumarède (2014) atribui o insucesso da conciliação na França do Oitocentos ao fracasso do poder judicial em obrigar as partes a comparecer diante dos juízes de paz. A modesta multa fixada em dez francos pela ausência à sessão de conciliação contribuiu para o descompromisso com a justiça concertadora. Em 1840, metade dos casos levados aos juízes de paz resultou na composição das partes na França. Em 1856, esse número caiu para um terço e, em 1890, para menos de um quarto. Para o Brasil, encontrou-se, inicialmente em algumas Freguesias do Rio de Janeiro, em 1830, números superiores ao da França. É o que se extrai de informações expostas pelo Aurora Fluminense em 17 de maio de 1830: das 430 conciliações intentadas, realizaram-se cerca de $63 \%$.

Nos relatórios dos Ministros de Justiça do Império, encontram-se dados mais extensivos sobre as conciliações em todo o país. Muitos dos ministros, porém, reconheciam certa imperfeição das estatísticas da época. Apurou-se para o Segundo Reinado as seguintes indicações sobre a prática da composição das partes:

Tabela 1. Conciliações e ações cíveis intentadas no Brasil - 1865-1874

\begin{tabular}{c|c|c|c|c|c|c|c|c|}
\hline \multirow{2}{*}{ ANO } & \multicolumn{3}{|c|}{ CONCILIAÇÕES } & \multicolumn{3}{c}{ AÇÕES CÍVEIS } \\
\cline { 2 - 11 } & Verificadas & $\%$ & $\begin{array}{c}\text { Não } \\
\text { verificadas }\end{array}$ & Totais & Ordinárias & Sumárias & Executivas & Totais \\
\hline $\mathbf{1 8 6 5}$ & 1.498 & 16,5 & 4.823 & 6.321 & 315 & 85 & 290 & 375 \\
\hline $\mathbf{1 8 6 6}$ & 2.623 & 32,1 & 6.444 & 9.067 & 318 & 1.388 & 995 & 2383 \\
\hline $\mathbf{1 8 6 7}$ & 2.384 & 25,9 & 5.789 & 8.173 & s/infor. & s/infor. & s/infor. & 3.460 \\
\hline $\mathbf{1 8 6 9}$ & 2.671 & 33,2 & 6.548 & 9.219 & 759 & 1.293 & 353 & 2.405 \\
\hline $\mathbf{1 8 7 0}$ & 4.656 & 74,1 & 3.395 & 8.051 & 801 & 1.331 & 490 & 1.989 \\
\hline $\mathbf{1 8 7 1}$ & 1.813 & 27,0 & 4.468 & 6.281 & 433 & 1.159 & 227 & 1819 \\
\hline $\mathbf{1 8 7 2}$ & 2.016 & 26,6 & 4.690 & 6.706 & ilegível & ilegível & ilegível & 2.167 \\
\hline $\mathbf{1 8 7 3}$ & 2.776 & 36,6 & 4.816 & 7.592 & 873 & 1.295 & 805 & 2.622 \\
\hline Totais & & & & 61.410 & & & & 17.220 \\
\hline
\end{tabular}

Fonte. BRASIL. Relatórios do Ministro e Secretário d'Estado dos Negócios da Justiça. 1865-1873. 
Observa-se na tabela o enorme afluxo por justiça através das audiências de conciliações. Enquanto se intentaram cerca de 61 mil conciliações no Brasil nos anos de 1865 a 1873, pouco mais de 17 mil casos foram submetidos aos procedimentos processuais civis. O gráfico abaixo demonstra a diferença da frequência entre as duas técnicas de resolução de conflito:

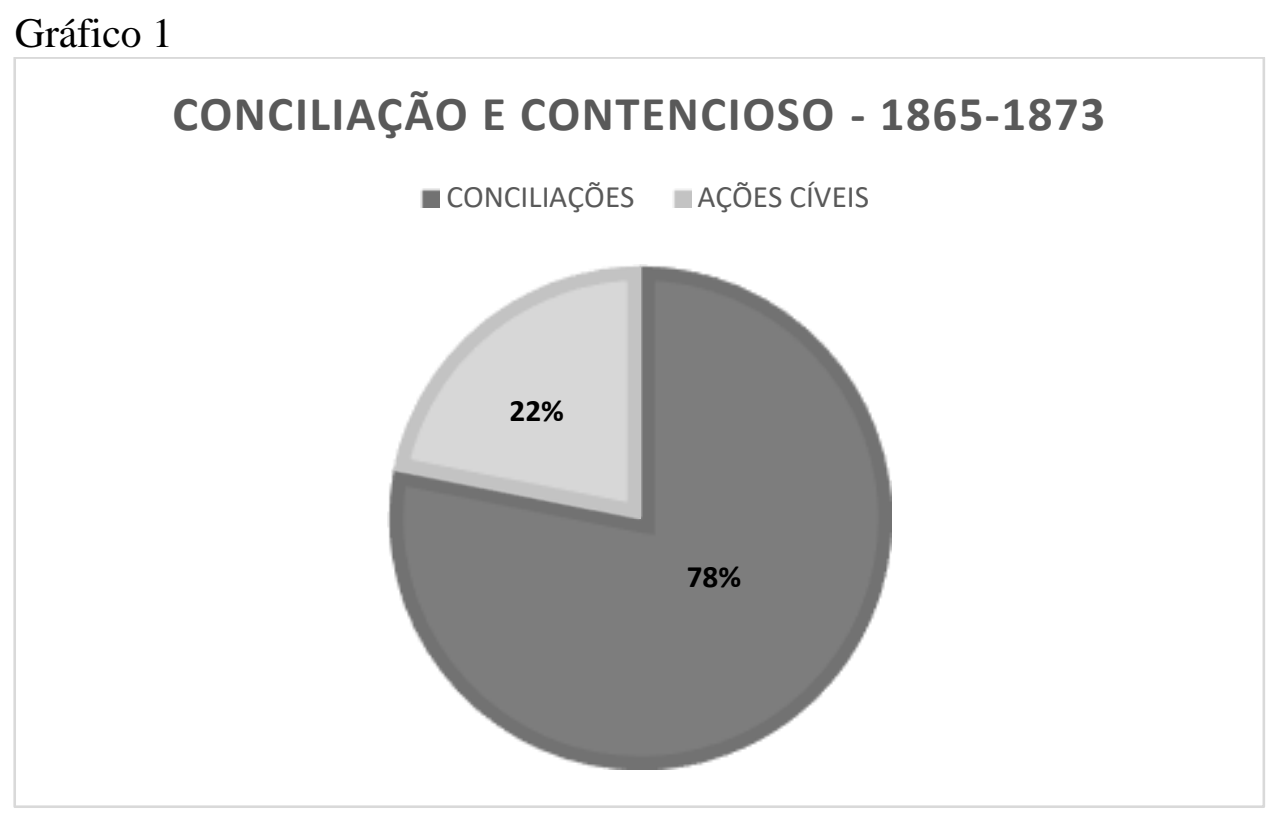

Majoritariamente, portanto, levavam-se aos juizados de paz conflitos sociais como alternativa de resolução. O problema, como se viu na França, foi a baixa eficácia da técnica. Veja abaixo o gráfico:

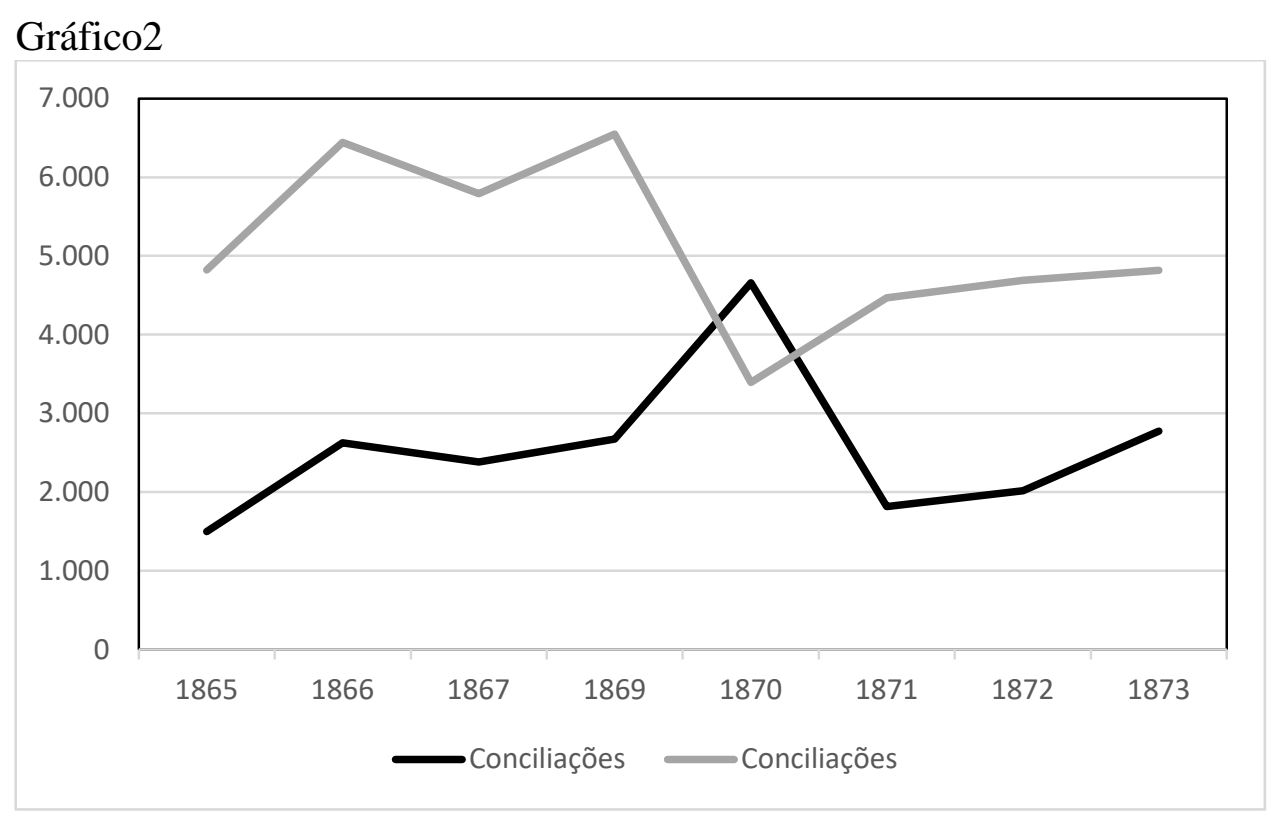

Em verdade, as conciliações alcançavam êxito parcial, uma vez que o procedimento lograva, em média, a composição de cerca de um terço dos casos. Como na França, o instituto encontrava barreiras importantes para sua exequibilidade. A revelia revelou-se empecilho relevantíssimo. As críticas à falta de efetividade da conciliação, assim, acompanhavam as censuras às autoridades conciliadoras - os juízes de paz. 
No final do século XIX, porém, acumulavam-se as críticas às leis civis do país. Nos termos de Ascarelli (1947, p. 100), a codificação, embora anunciada como necessária pela elite política brasileira, confrontava-se com o peso da tradição jurídica enraizada no direito comum europeu do século XVIII, especialmente as ordenações Filipinas. Patrícia Gomes (2014, p. 47) relata os ardis em torno da escolha dos autores dos projetos de código civil no Império, cuja escolha recaiu sobre homens como Teixeira de Freitas, Nabuco de Araújo e Joaquim Felício. Mesmo que se tratasse de pessoas abnegadas no cumprimento da importante missão, não houve êxito em prover o Império daquela desejada lei. Pode-se arguir, como o fez Ricardo Fonseca (2006), que a ampla rejeição à ideia de codificação se devia às elites regionais e locais, ciosas em preservar seus círculos privados de poder, e à população em geral, distante de se constituir como comunidade política. A demorada espera apenas revela a cultura jurídica brasileira firmemente ancorada no direito romano e na hermenêutica supletória das leis.

Importante observar que as mudanças proporcionadas pelo fim da escravidão e a implantação da República reclamavam soluções imprevistas pela antiga cultura jurídica. Ao fim do século, o país encontrava-se imerso em profunda crise política, social e econômica. A modernização deixara o campo da retórica da elite para se tornar uma necessidade. Os antigos preceitos legais embaraçavam o matrimônio entre católicos e protestantes, exatamente quando afluíam europeus de diversas religiões reformadas. Além disso, difundia-se no país o conceito da superioridade racial dos europeus, independentemente de sua filiação religiosa (NEDER, 2017, p. 130).

Na República, segundo Lynch (2017, p. 159), o positivismo e o evolucionismo formavam o novo ideário de oposição ao antigo Regresso, movimento conservador e centralizador que se instalou a partir dos anos de 1940 no país para combater as forças centrífugas responsáveis pelos tumultos e revoltas regenciais. Partidários do federalismo rebelaram-se contra o centralismo monárquico regressista em nome das liberdades de comércio e individual e da separação entre Igreja e Estado. Nesse contexto, finalmente, tornaram-se concretas as condições para o movimento codificador se completar no Brasil. Como afirmou Campos Salles (BRASIL, 1891, p. 14),

[...] a consequente alteração de instituições que, já condenadas pela própria monarquia, se tornavam de todo o ponto incompatíveis com a república federativa, convenceram desde logo o Governo Provisório de que, sem revisão das leis civis e decretação de reformas e disposições complementares, impossível lhe era satisfazer as exigências da situação.

Os constituintes, em 1890/91, dividiram-se em relação à competência dos entes da federação em legislar. Os deputados partidários de um governo central forte defendiam a concentração da competência legislativa no congresso federal, enquanto federalistas mais radicais compreendiam ser direito dos Estados estabelecer suas próprias normativas. Ao final dos debates, ao Congresso se encarregou o direito substantivo e, aos legislativos estaduais, se entregaram as leis processuais, com exceção, é claro, dos procedimentos atinentes à Justiça Federal. Muitos estados da Federação prepararam seus códigos civis ou legislações congêneres. Na primeira década do século XX, Pará, Rio Grande do Sul, Maranhão e o Distrito Federal produziram seus códigos. Na década seguinte, foi a vez de Espírito Santo, Bahia, Rio de Janeiro, Paraná, Piauí e Sergipe. Finalmente, entre 1921 e 1930, preparam suas leis processuais Ceará, Minas Gerais, Rio Grande do Norte, Pernambuco, Santa Catarina, São Paulo e Paraíba. Goiás, Alagoas e Amazonas parecem não ter produzido semelhante lei (DUARTE e KOERNER, 2014, p. 21 e 22).

No entanto, antes dessas iniciativas, o Ministro Campos Salles determinou a aplicação da lei sobre o processo comercial de 1850 às ações e execuções cíveis (BRASIL, 1890b). A conciliação mantinha-se, assim, como elementar para início de qualquer causa no juízo contencioso, já que a lei comercial regulava, em seu artigo 23, que: "Nenhuma causa comercial 
será proposta em Juízo contencioso, sem que previamente se tenha tentado o meio da conciliação, ou por ato judicial, ou por comparecimento voluntário das partes".

Essa legislação se alterava, naturalmente, com a promulgação dos códigos processuais estaduais. O Código de Processo Civil e Comercial do Espírito Santo, de 1914, por exemplo, aboliu o conceito de conciliação. A legislação capixaba admitia, contudo, o processo arbitral, ao qual dedicou o Título $\mathrm{X}$ do código e o disciplinou em 27 artigos. Já o código paulista, promulgado em 1930, manteve o instituto da conciliação, dedicando-lhe um capítulo com quatro artigos. Estudiosos apontam que os códigos estaduais pouco se distanciavam do regulamento 737, de 1850, o que perpetuou sua influência no direito processual brasileiro até 1939 (ALMEIDA, 2016, p. 169).

A tendência descentralizadora e federalista decairia juntamente com a Primeira República. Em parte, os moços da elite seduziram-se pelas correntes antiliberais que ganhavam força pelo mundo. Defendiam, como bem aponta Ângela Gomes (2014, p. 15), o intervencionismo estatal e a governabilidade sobre a sociedade. A Constituição de 1934 reverteu para o Congresso o poder de legislar sobre o direito processual, por meio de artigo $5^{\circ}$, item XIXa. No entanto, o código de processo civil nacional somente sobreviria com o Estado Novo.

Essas forças antiliberais que ascenderam na Primeira República ganharam terreno no país e instalaram um regime marcado pelo autoritarismo e intervencionismo. Nova constituição, que manteve a competência privativa da União para legislar a respeito do processo, foi outorgada em 1937. A modernidade requerida pelo novo regime exigia ainda mais novas leis ordinárias que melhor traduzissem a ideologia discricionária.

O ministro da justiça, Francisco Campos, encarregou-se pessoalmente da revisão do anteprojeto do código que foi, enfim, promulgado em 1939 (ALMEIDA, 2016, p. 170). O primeiro código nacional de processo civil apenas reconheceu, por meio do artigo 646, a possibilidade de reconciliação para o restabelecimento de união entre cônjuges, mas exigia requerimento ao juízo, assinado pelo casal, e homologado por sentença.

Pode-se indagar o porquê de mudança tão drástica em relação ao procedimento. A exposição de motivos que antecede o código foi escrita pelo próprio Francisco Campos, que criticou as leis anteriores pela falta de técnica e confusão. Apresentou a nova norma como exemplo de modernidade:

À concepção dualística do processo haveria de substituir-se a concepção autoritária do processo. À concepção do processo como instrumento de luta entre particulares, haveria de substituir-se a concepção do processo como instrumento de investigação da verdade e de distribuição da justiça.

Essa reforma do processo, destinada a pôr sob a guarda do Estado a administração da justiça, subtraindo-a à discrição dos interessados, tem um sentido altamente popular (CAMPOS, 1939).

A nova legislação aboliu a conciliação como procedimento prévio obrigatório para o ajuizamento das ações judiciais, sob a justificativa da ineficiência e onerosidade desse procedimento. O declínio do instituto da conciliação decorreu, assim, do crescente formalismo jurídico, que não permitia alternativas de solução de conflitos por métodos colaborativos. Ademais, advogava-se a concentração de poderes do juiz togado, como expressou Campos (1939):

O princípio de concentração imediatiza o contato do juiz com o processo e exige que todos os atos e incidentes ocorridos na mesma audiência sejam objeto de solução imediata por parte do juiz. As atividades processuais desenvolvem-se em uma ou mais audiências e, no último caso, em audiências tão próximas quanto possível umas das outras, de maneira que a decisão sobrevenha quando 
ainda não se apagaram no espírito do juiz as impressões e o interesse que lhe haja despertado o curso do processo. [...].

$\mathrm{O}$ princípio que deve reger a situação do juiz em relação à prova e o de concentração dos atos do processo postulam, necessariamente, o princípio da identidade física do juiz. O juiz que dirige a instrução do processo há de ser o juiz que decida o litígio. Nem de outra maneira poderia ser, pois, o processo visando a investigação da verdade, somente o juiz que tomou as provas esta realmente habilitado a apreciá-las do ponto de vista do seu valor ou da sua eficácia em relação aos pontos debatidos.

A Consolidação das Leis do Trabalho, já em 1943, foi responsável por trazer de volta a conciliação no ordenamento jurídico, restrita ao processo trabalhista, com previsão de dupla tentativa de conciliação proposta pelo juiz: uma após a defesa do reclamado (artigo 847) e outra após a instrução probatória (artigo 850). A retomada da conciliação também ocorreu por meio da promulgação do novo Código de Processo Civil, lei n. 5.869 de 1973, que a previu tanto em procedimentos sumários quanto ordinários. O artigo 277 incluía a conciliação como etapa necessária, a ser realizada no prazo de trinta dias depois de proposta a ação, se considerada atinente aos procedimentos sumários. Para a Fazenda Pública, o prazo se contava em dobro. O parágrafo primeiro do mesmo artigo admitia, inclusive, a figura de um conciliador para auxiliar o juiz de Direito.

Já no procedimento ordinário, o código processual de 1973 designaria audiência de conciliação apenas se a causa admitisse transação. A realização da concertação deveria, como nos procedimentos sumários, ocorrer no prazo de trinta dias. Caso não se obtivesse o consenso entre as partes, então se iniciariam as fases saneadoras e instrutórias. Dessa descrição, pode-se afirmar que, sob a sistemática do Código de Processo Civil de 1973, a conciliação era instrumento endoprocessual, ou seja, mecanismo de resolução de conflitos a ser utilizado no processo, como ato processual.

Outra possibilidade de conciliação ocorria diante de embargos propostos pelo executado. Nessas circunstâncias, o juiz podia designar audiência de conciliação (artigo 740). Já nas causas relativas à família (artigos 447 a 449), ao magistrado obrigava-se intentar a conciliação, depois do que, diante da manutenção da vontade de desfazer o matrimônio, se iniciava a lide.

Marcelo Abelha (2016) enfatiza, porém, que as previsões do código processual de 1973 mostraram-se incipientes, com pouca fluência e efetividade. O jurista atribui o insucesso, entre outras causas, ao enorme quantitativo de processos envolvendo relações de consumo que se multiplicam e impedem que o Judiciário promova o princípio da duração razoável do processo com a mesma estrutura, já ultrapassada.

Registre-se, aliás, que, o princípio da duração razoável do processo é um elemento indispensável ao princípio da justiça: "o direito de acesso à justiça exige que o Estado preste a adequada tutela jurisdicional que, para esses autores, significa, também, a tutela estatal tempestiva e efetiva". (MARINONI e ARENHART, 2001, p. 50)

\section{CONCILIAÇÃO COMO TRATAMENTO PROCESSUAL ADEQUADO}

Dentre os obstáculos do acesso à justiça, Michele Souza e Kelly Gandra (2013, p. 567569) destacaram, em primeiro lugar, as custas em geral, tanto aquelas pagas com honorários advocatícios, quanto as remuneratórias do Estado para administração do litígio. Em segundo, o tempo do litígio, que só contribui para elevar seus custos. E, em terceiro, o caráter dos direitos difusos, pois, apesar de muitas vezes necessitarem de intervenção judicial para sua proteção, os titulares ou beneficiários de direitos preferem esperar a atuação governamental. Pode-se, portanto, afirmar que o modelo formal adjudicatório que depende do Estado-juiz para a solução 
do litígio das partes produz sérias dificuldades na resolução de conflitos sociais com observância dos princípios constitucionais da duração razoável do processo e da justiça.

O ordenamento jurídico tem vislumbrado no instituto da conciliação uma alternativa para solucionar o problema da insuficiência do Poder Judiciário, retomando a valorização da conciliação como alternativa de solução de conflitos e utilizando juízes leigos como auxiliares da Justiça. A conciliação, seja em fase pré-processual ou mesmo processual, tem-se mostrado eficiente forma alternativa à jurisdição estatal para pôr fim ao conflito de interesses entre as partes de modo simples, eficaz, acessível e célere, evitando a movimentação desnecessária da máquina judiciária.

Não por outra razão, a Constituição de 1988 inovou, ao determinar a criação de Juizados Especiais e ao instituir a figura dos juízes leigos, atribuindo-lhes funções de conciliação e auxílio no julgamento de causas de menor complexidade, bem como ao fazer expressa previsão da justiça de paz com a incumbência de promover a conciliação. Ainda assim esse comando mantém-se inerte. A Procuradoria Geral da República ajuizou, no ano de 2017, Ação Declaratória de Inconstitucionalidade por Omissão (ADO n. 40) contra diversos Tribunais, em razão de não regulamentarem o teor do artigo 98, II da Constituição Federal, e não instituírem e regulamentarem a Justiça de Paz e o processo eleitoral para escolha dos juízes de paz (BRASIL, 2017).

Atento a essa insuficiência do modelo tradicional de jurisdição estatal que, em sua atual conjuntura, mostra-se incompatível com os princípios da duração razoável do processo e da justiça, o Conselho Nacional de Justiça (CNJ) tem identificado na conciliação um instrumento capaz de assegurar uma resolução adequada dos conflitos e de concretizar as garantias constitucionais do jurisdicionado.

Nesse sentido, o CNJ editou a Resolução n. 125, de 29 de novembro de 2010, a qual indica a conciliação como instrumento efetivo de pacificação social, solução e prevenção de litígios, capaz de reduzir a excessiva judicialização dos conflitos de interesses. Em razão disso, instituiu-se a Política Judiciária nacional de tratamento dos conflitos de interesses, que ressalta a importância dos mecanismos de solução de controvérsia diferentes da solução adjudicada, em especial os meios consensuais, como a conciliação.

Nessa Política Judiciária nacional de tratamento dos conflitos de interesses, diversas medidas foram adotadas para se incentivar e promover a conciliação, entre as quais merece destaque a consideração do desempenho na atividade conciliatória dos magistrados para fins de promoção por merecimento; criação de sistema de conciliação digital para busca da resolução de conflitos de forma autocompositiva em fase pré-processual; criação de selo de qualidade para avaliar as empresas que resolvem ou não os seus litígios mediante a autocomposição, entre outras.

Outras medidas normativas editadas pelo Conselho Nacional de Justiça buscam a promoção da conciliação como método de resolução de conflitos, como a Recomendação n. 50 de 08 de maio de 2014. A partir da nova política de tratamento dos conflitos, o Conselho Nacional de Justiça passou a incluir, em 2016, no seu relatório anual, dados sobre a efetividade das conciliações realizadas nos processos judiciais no Poder Judiciário brasileiro.

Novo indicador também apresentado é o índice de homologação de acordos, revelando, também ineditamente, o resultado das políticas de estímulo à conciliação e à mediação no Brasil, uma das linhas de atuação do Conselho Nacional de Justiça desde a sua implantação. Mostra-se também o índice de conciliação como medida inicial para avaliar as consequências das recentes alterações determinadas pelo novo Código de Processo Civil, conferindo-se maior relevo ao relatório neste novo contexto legal. (BRASIL, 2016, p. 5) 
Os dados apresentados pelo CNJ, em 2016, são referentes a processos submetidos aos procedimentos do Código de Processo Civil de 1973, tendo em vista que se referem ao ano-base 2015 (somente tendo o Novo CPC iniciado sua vigência em 18/03/2016). Nas estatísticas apresentadas para o ano de 2017, parcialmente, considerou-se a vigência do novo CPC. No entanto, as informações provisórias demonstram que a conciliação ainda precisa ser incentivada e melhor desenvolvida, apresentando ainda índices abaixo dos esperados para se amenizar o atual quadro de insuficiência do Poder Judiciário.

Sob uma perspectiva geral, em 2015, em média 9,4\% das sentenças e decisões foram homologatórias de acordos, enquanto, em 2016, registrou-se pequeno crescimento alcançando média de 11,9\% (BRASIL, 2016, p. 99; BRASIL, 2017, p. 123). Dos dados fornecidos pelo CNJ, elaborou-se o seguinte gráfico:

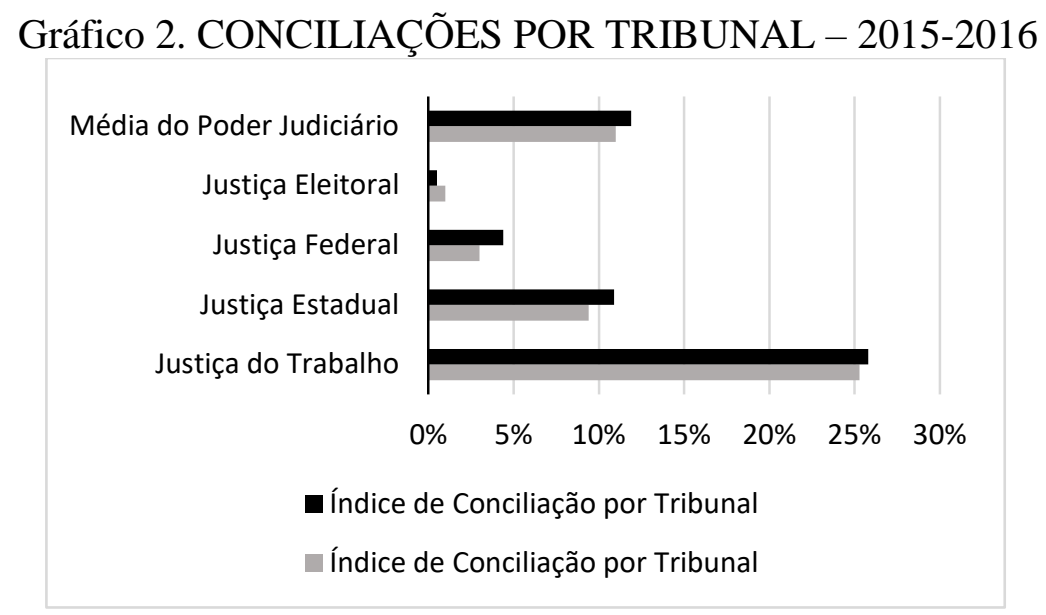

Entretanto, o referido gráfico traz uma abordagem geral da Justiça Estadual (órgão judiciário mais diretamente afetado pelas disposições do Código de Processo Civil), considerando dados de processos que tramitam em segunda instância e em fase de execução, nos quais, naturalmente, há menor probabilidade de se resolver um conflito por meio de conciliação (isso porque, nessas fases processuais, uma das partes já possui um provimento judicial a ela favorável, permitindo-lhe a adjudicação do seu interesse, não havendo, como regra, pretensão de conciliar). Se analisarmos os dados de conciliações na primeira instância, o resultado já se mostra mais promissor como eficiente método de resolução adequada de conflitos.

Tabela 1. Índice de Conciliação de $1^{\circ}$ Grau

\begin{tabular}{|l|l|l|l|l}
\hline \multicolumn{2}{l|}{ Execução } & & \multicolumn{2}{l}{ Conhecimento } \\
\hline $\mathbf{2 0 1 6}$ & 2015 & & 2015 & 2016 \\
\hline $\mathbf{6 \%}$ & $5 \%$ & Justiça do Trabalho & $40 \%$ & $5 \%$ \\
\hline $\mathbf{5 \%}$ & $4 \%$ & Justiça Estadual & $14 \%$ & $15 \%$ \\
\hline $\mathbf{8 \%}$ & $3 \%$ & Justiça Federal & $5 \%$ & $6 \%$ \\
\hline $\mathbf{5 \%}$ & $4 \%$ & Poder Judiciário & $17 \%$ & $17 \%$ \\
\hline
\end{tabular}

Fonte: BRASIL, 2017; 2016.

As inovações do Novo Código de Processo Civil de 2015 certamente promoverão mais avanços na efetividade da conciliação como método adequado de resolução de conflitos, em especial com a antecipação da audiência de conciliação. Esperam-se os efeitos positivos, especialmente do artigo 334, com expressa recomendação da conciliação antecipando a apresentação da resistência pela parte contra a qual se ajuizou ação e a instalação do litígio. Além disso, deve-se destacar a possibilidade de se realizar mais de uma audiência de conciliação, o que 
facilita a composição das partes. E, ainda, a realização de audiência de conciliação por pessoa diversa do juiz, o que traz menor formalidade para o ato e ainda permite a discussão de hipóteses de acordos possíveis, sem o receio de que qualquer proposta seja levada em consideração pelo juiz como reconhecimento de procedência ou improcedência de qualquer dos pedidos.

\section{CONCLUSÃO}

A conciliação, como exposto neste artigo, compõe a tradição jurídica brasileira desde os tempos de colonização portuguesa. Tornou-se instituto constitucional em 1824, sem o que não se iniciava nenhum processo no país. No Brasil República, a conciliação foi relegada pelo ordenamento jurídico, seja pela alta incidência de revelia, seja pela influência do formalismo jurídico. Manteve-se fracamente disciplinada na primeira República por meio da manutenção do antigo Decreto 737 de 1850 e pelos novos códigos processuais estaduais. Depois de 1930, a conciliação foi relegada a um plano muito secundário em face do fortalecimento de uma concepção autoritária de processo pelo código de 1939.

Nessa longa trajetória, deve-se distinguir a luta entre uma cultura jurídica fundada na tradição do direito comum do século XVIII e a cultura jurídica positivista e formalista inaugurada com a Constituição de 1934 e reforçada com o Estado Novo. A partir da década de 1970, porém, a conciliação voltou ao ordenamento jurídico para se tornar, em 1988, novamente preceito constitucional. Nota-se o trânsito da cultura jurídica formalista e autoritária dos anos de 1930 para uma nova cultura, que concebe o processo além do contencioso.

Ainda assim, se deve salientar que o ideal de autonomia das federações não alcançou grande êxito na República brasileira. Concernente à conciliação, as iniciativas mais importantes encontram-se fundadas na União. Nesse sentido, o Conselho Nacional de justiça promove inúmeras políticas para guindar as técnicas de composição das partes a um lugar proeminente no tratamento dos conflitos levados ao judiciário.

\section{REFERÊNCIAS BIBLIOGRÁGICAS}

\section{Documentos}

BRASIL. Constituição Política do Império do Brazil, de 25.03.1824. Rio de Janeiro, 1824. Disponível em: 〈http://www.planalto.gov.br/ccivil_03/constituicao/constituicao24.htm>. Acesso em 18 jan 2017.

BRASIL. Relatório do ano de 1833 apresentado à Assembleia Geral Legislativa na Sessão Ordinária de 1834. Rio de Janeiro: Ministério da Justiça, 1834.

BRASIL. Relatório do ano de 1834 apresentado à Assembleia Geral Legislativa na Sessão Ordinária de 1835. Rio de Janeiro: Ministério da Justiça, 1835.

BRASIL. Resolução Imperial de 28 de dezembro de 1876. Rio de Janeiro.

BRASIL. Decreto N. 359, de 26 de abril de 1890. Rio de Janeiro, 1890a. Disponível em: <http://www2.camara.leg.br/legin/fed/decret/1824-1899/decreto-359-26-abril-1890-506287publicacaooriginal-1-pe.html>. Acesso em: 25 jan 2017. 
BRASIL. Decreto N. 763, de 19 de setembro de 1890. Rio de Janeiro, 1890b. Disponível em <http://www.planalto.gov.br/ccivil_03/decreto/1851-1899/D763.htm>. Acesso em: 28/09/2017.

BRASIL. Exposição apresentada ao Chefe do Governo Provisório da República dos Estados Unidos do Brasil pelo General Dr. Manoel Ferraz de Campos Salles, Ministro e Secretário de Estado dos Negócios da Justiça. Rio de Janeiro: Imprensa Nacional, 1891. Disponível em: < http://memoria.bn.br>. Acesso em: 28 set. 2017.

BRASIL. Decreto-Lei N.1.608, de 18.09.1939. Rio de Janeiro, 1939. Disponível em: <http://www.planalto.gov.br/ccivil_03/decreto-lei/1937-1946/Del1608.htm>. Acesso em: 25 jan 2017.

BRASIL. Lei N. 5.869, de 11.01.1973. Brasília, 1973. Disponível em: < http://www.planalto.gov.br/ccivil_03/leis/L5869impressao.htm>. Acesso em 25 jan 2017.

BRASIL. Lei N. 7.244, de 7 de novembro de 1984. Brasília. Disponível em: < http://www.planalto.gov.br/ccivil_03/leis/1980-1988/L7244.htm>. Acesso em: 25 jan 2017.

BRASIL. Lei n. ${ }^{\text {o }}$ 9.099, de 26.09.1999. Brasília. Disponível em: < http://www.planalto.gov.br/ccivil_03/leis/L9099.htm>. Acesso em 25 jan 2017.

BRASIL. Lei n. ${ }^{\circ}$ 9.958, de 12.01.2000. Brasília. Disponível em: <https://www.planalto.gov.br/ccivil_03/leis/L9958.htm>. Acesso em 25 jan 2017.

BRASIL. Supremo Tribunal Federal. Ação Direta de Inconstitucionalidade n. ${ }^{\circ} 2.139$ e 2.160. Relator: Ministro Marco Aurélio Mello. 23 de outubro de 2009. Disponível em: $<$ http://www.stf.jus.br/portal/processo/verProcessoAndamento.asp?incidente=1804602>. Acesso em 25 jan 2017.

BRASIL. Conselho Nacional de Justiça. Tribunais de Justiça contratam juízes leigos para reforçar Juizados Especiais. Brasília. 2015. Disponível em: <http://www.cnj.jus.br/noticias/cnj/80753-tribunais-de-justica-contratam-juizes-leigos-parareforcar-juizados-especiais>. Acesso em 01 set. 2017.

BRASIL. Lei N. 13.105, de 16.03.2015. Brasília. Disponível em: <http://www.planalto.gov.br/ccivil_03/_ato2015-2018/2015/lei/113105.htm>. Acesso em 25 jan 2017.

BRASIL. Conselho Nacional de Justiça. Justiça em números 2016: ano-base 2015. v. II. Brasília: CNJ, 2016. Disponível em: < http://www.cnj.jus.br/files/conteudo/arquivo/2017/05/4c12ea9e44c05e1f766230c0115d3e14.pdf> . Acesso em: 31 ago. 2017.

BRASIL. Conselho Nacional de Justiça. Justiça em números 2017: ano-base 2016. v. II. Brasília: CNJ, 2017. Disponível em: http://www.cnj.jus.br/files/conteudo/arquivo/2016/10/b8f46be3dbbff344931a933579915488.pdf> . Acesso em: 3 out. 2017. 
BRASIL. Conselho Nacional de Justiça. Mediação e conciliação, qual a diferença?. Brasília. Disponível em: < http://www.cnj.jus.br/programas-e-acoes/conciliacao-e-mediacao-portal-daconciliacao>. Acesso em 18 jan 2017.

BRASIL. Conselho Nacional de Justiça. O que faz o juiz leigo?. Brasília. Disponível em: <www.cnj.jus.br/noticias/cnj/62451-o-que-faz-o-juiz-leigo>. Acesso em: 18 jan 2017.

BRASIL. Supremo Tribunal Federal. Ação Declaratória de Inconstitucionalidade por Omissão n. 40, Ministério Público Federal (autor) e Tribunal de Justiça do estado do Acre e outros (requeridos). Brasília, 04 de abril de 2017.

ESPANHA. La Constitucion Española de 1812. Disponível em: <https://es.wikisource.org/wiki/Constituci\%C3\%B3n_espa\%C3\%B1ola_de_1812\#CAP.C3.8DT ULO_II._De_la_Administraci.C3.B3n_de_Justicia_en_lo_Civil>. Acesso em 23 set. 2017.

FRANÇA. La Constitution de 1791. Disponível em: < http://www.conseilconstitutionnel.fr/conseil-constitutionnel/francais/la-constitution/les-constitutions-de-lafrance/constitution-de-1791.5082.html>. Acesso em 23 set. 2017.

PORTUGAL. Constituição portuguesas de 1822. Disponível em: <http://www.arqnet.pt/portal/portugal/liberalismo/c1822t5.html >. Acesso em 23 set. 2017.

\section{Bibliografia}

ABELHA, Marcelo. Manual de direito processual civil. 6. ed. Rio de Janeiro: Forense, 2016.

ALMEIDA, Guarino Sant'Anna Lima de et all. Argumentos de justificação para as reformas processuais; uma análise semiolinguística das exposições de motivos do Código Civil de 1939 e do Anteprojeto de Reforma de 2010. Revista de Estudos Empíricos em Direito, São Paulo, 2016, vol 3, n. 2, p. 162-182.

ASCARELLI, Tullio. Osservazioni di diritto comparato privato italo-brasiliano. Il Foro Italiano, Itália, vol. 70, p. 97-110.

CAMPOS, Adriana Pereira e SOUZA, Alexandre de Oliveira Bazílio. A Conciliação e os Meios Alternativos de Solução de Conflitos no Império Brasileiro. Revista de Ciências Sociais, Rio de Janeiro, vol. 59, n. 1, 2016. p. 271-298.

CAMPOS, Adriana Pereira; VELLASCO, Ivan. Juízes de Paz, mobilização e interiorização da política. In: CARVALHO, José Murilo; CAMPOS, Adriana (Org.). Dimensões da Cidadania. Rio de Janeiro: Civilização Brasileira, 2011.

CAMPOS, Adriana Pereira. Juízes de paz no Brasil do Oitocentos: uma experiência cidadã. In FERREIRA, Fátima Moura; MENDES, Francisco Azevedo; CAPELA, José Viriato. Justiça na res publica (sécs. XIX-XX): ordem, direitos individuais e defesa da sociedade. Braga: Citem, 2011. p. 191-201. 
CAMPOS, Francisco. Exposição de motivos: ao código de processo civil. Rio de Janeiro, 1939. Disponível em: < http://www2.camara.leg.br/legin/fed/declei/1930-1939/decreto-lei-1608-18setembro-1939-411638-norma-pe.html>. Acessível em: 29 set. 2017.

CARVALHO, Jorge Brandão. Tensões numa comunidade rural do Baixo-Minho: Adaúfe e o seu juízo de Paz (1835-1880). Braga: Universidade do Minho, 1999.

CARVAlHO, José Murilo. Cidadania: tipos e percursos. Estudos Históricos. Rio de Janeiro, n.18, 1996. p. 337-360.

CHAGAS, Bárbara Seccato Ruis. O tratamento adequado de conflitos no processo civil brasileiro. Dissertação (Mestrado) - Programa de Pós-Graduação Stricto Sensu em Direito Processual da Universidade Federal do Espírito Santo. Vitória, 2017.

CAYRES, Nelson A. Vem ai o novo CPC. Direito em ação, Brasília, v.9 n.1, jul./dez. 2012. p. 13-46.

CODA, Alexandra. Os eleitos da Justiça: a atuação dos juízes de paz em Porto Alegre (18271841). Dissertação (Mestrado em História) — Programa de Pós-Graduação em História, UFRGS, Porto Alegre, 2012.

COSTA, Mário Júlio de Almeida. História do direito português. $5^{\mathrm{a}}$ ed. Coimbra: Almedina, 2011.

DEMARCHI, Juliana. Mediação: proposta de implementação no processo civil brasileiro. Tese (Doutorado em Direito) - Programa de Pós-Graduação em Direito Processual Civil da Universidade de São Paulo, São Paulo, 2007.

DIDIER JR., Fredie. Curso de direito processual civil: introdução ao direito processual civil, parte geral e processo de conhecimento. 17 a ed. Salvador: Jus Podivm, 2015.

DUARTE, Fernanda; KOERNER, Andrei. O pensamento jurídico publicista brasileiro. CONGRESSO DA BRASA, Londres, 2014.

FLORY, Thomaz. El juez de paz y El jurado em El Brasil imperial (1808-1871). México: Fondo de Cultura Economia, 1986.

FONSECA, Ricardo Marcelo. A cultura jurídica brasileira e a questão da codificação civil no século XIX. Revista da Faculdade de Direito da UFPR, 2006, v. 44, p. 61-76.

GOMES, Patrícia Regina Mendes Mattos Corrêa. Pensamento e ação de Joaquim Felício dos Santos: um projeto de código civil oitocentista. Programa de Pós-Graduação em Direito da Universidade de São Paulo (Mestrado). São Paulo: 2014.

HOMEM, António Pedro Barbas. Judex perfectus: função jurisdicional e estatuto judicial em Portugal, 1640-1820. Coimbra: Almedina, 2003. 
LYNCH, Christian Edward Cyril. República, evolucionismo e código civil: a presidência Campos Sales e o projeto Clóvis Beviláqua. $R$. IHGB, Rio de Janeiro, jan./mar 2017, a. 178, n. 473, p. 157-180.

MAGANO, Octávio Bueno. Direito e repressão. Arquivos do Ministério da Justiça. Brasília, n. 167, v. 39, p. 41-46, nov. 1985.

MARINONI, Luiz Guilherme; ARENHART, Sérgio Cruz. Manual do processo de conhecimento. São Paulo: Revista dos Tribunais, 2001.

MARQUES, Alessandra Garcia. A solução de conflitos dentro e fora do processo por meio da mediação no ordenamento jurídico brasileiro: uma necessária contribuição do pensamento de Emmanuel Levinas sobre e a alteridade para a reflexão a respeito da mediação. Revista de Direito Brasileira, São Paulo/SP, set./dez. 2016, v. 15, n. 6, p. 200-222.

MAZZEI, Rodrigo (Org.). Código de processo civil do Espírito Santo: texto legal e breve notícia histórica, 2014.

MENDONÇA, José Xavier de Carvalho de. Tratado theorico e prático das justiças de paz. Rio de Janeiro, Garnier, 1889.

MORAIS, José Luiz Bolzan de. Mediação e arbitração: alternativas à jurisdição. Porto Alegre: Livraria do advogado, 1999.

MOTTA, Kátia Sausen. Juiz de paz e cultura política no início do Oitocentos (Província do Espírito Santo, 1827-1842). Dissertação (Mestrado em História). Programa de Pós-Graduação em História, Universidade Federal do Espírito Santo, Vitória, 2013.

MOURA, Danielle Figuerêdo. Defensores de cabanos? A imagem dos juízes de paz em questão. Pará, 1836-1839. In: SEMINÁRIO INTERNACIONAL DA SOCIEDADE BRASILEIRA DE ESTUDOS DO OITOCENTOS, 2., 2017, Rio de Janeiro. Anais do II Seminário Internacional da Sociedade Brasileira de Estudos do Oitocentos. Rio de Janeiro: SEO, 2017. v. 2, p. 7. Disponível em: <www.seo.uff.br>. Acesso em: 28 jan. 2017.

NEDER, Gizlene. Clóvis Beviláqua: redes de sociabilidade política, reconhecimento e ressentimento. R. IHGB, Rio de Janeiro, jan./mar 2017, a. 178, n. 473, p. 125-156.

POUMARÈDE, Jacques. Histoire de la conciliation. Disponível em: <https://www.conciliateurs.fr/Histoire-de-la-Conciliation>. Acesso em: 24 set. 2017.

RIBAS, Antonio Joaquim; RIBAS, Júlio Adolpho. Consolidação das leis do processo civil. Rio de Janeiro: Dias da Silva Junior, 1879.

RIBEIRO, José Silvestre. Resoluções do Conselho de Estado da secção do contencioso administrativos colligidas e explicas por José Silvestre Ribeiro. Lisboa: Imprensa Nacional, 1855. Tomo III. Disponível em: 
https://books.google.com.br/books?id=JcMtAAAAYAAJ\&pg=PA180\&dq=concertadores+em+P ortugal\&hl=pt-

BR\&sa=X\&ved=0ahUKEwisy5WAqbzWAhUPmJAKHd8CDIoQ6AEIODAD\#v=onepage \&q=c oncertadores $\% 20 \& \mathrm{f}=$ false. Acesso em: 23 set. 2017.

SALES, José Roberto da Cunha. Tratado da praxe conciliatória ou teoria e prática das conciliações e da pequena demanda. Rio de Janeiro: Nicolau d'Oliveira, 1879.

SLEMIAN, Andréa. Sob o império das leis: Constituição e unidade nacional na formação do Brasil (1822-1834). São Paulo: Hucitec/Fapesp, 2009.

SILVA, Nuno J. Espinosa Gomes. História do Direito Português: fontes de direito. $2^{\mathrm{a}}$ ed. Lisboa: Fundação Calouste Gulbenkian, 1991.

SOUZA, Michele Faria de; GANDRA, Kelly Cristine de Campos. A crise do judiciário e a mediação como uma forma alternativa para resolução de conflitos familiares. Revista de Direito Brasileira, [S. 1.], set. 2013, v. 4, n. 3, p. 561-591. 